\title{
Connected arrays of dipoles for broad band, wide angle scanning, dual polarized applications : a novel solution to the common mode problem
}

\author{
Citation for published version (APA): \\ Cavallo, D., Neto, A., Gerini, G., \& Smits, F. (2010). Connected arrays of dipoles for broad band, wide angle \\ scanning, dual polarized applications : a novel solution to the common mode problem. In Proceedings of the \\ 2010 IEEE International Symposium on Phased Array Systems and Technology (ARRAY), 12-15 October 2010, \\ Waltham, Massachussetts (pp. 906-910). Institute of Electrical and Electronics Engineers. \\ https://doi.org/10.1109/ARRAY.2010.5613253
}

DOI:

10.1109/ARRAY.2010.5613253

Document status and date:

Published: 01/01/2010

\section{Document Version:}

Publisher's PDF, also known as Version of Record (includes final page, issue and volume numbers)

\section{Please check the document version of this publication:}

- A submitted manuscript is the version of the article upon submission and before peer-review. There can be important differences between the submitted version and the official published version of record. People interested in the research are advised to contact the author for the final version of the publication, or visit the DOI to the publisher's website.

- The final author version and the galley proof are versions of the publication after peer review.

- The final published version features the final layout of the paper including the volume, issue and page numbers.

Link to publication

\footnotetext{
General rights

- You may freely distribute the URL identifying the publication in the public portal. follow below link for the End User Agreement:

www.tue.nl/taverne

\section{Take down policy}

If you believe that this document breaches copyright please contact us at:

openaccess@tue.nl

providing details and we will investigate your claim.
}

Copyright and moral rights for the publications made accessible in the public portal are retained by the authors and/or other copyright owners and it is a condition of accessing publications that users recognise and abide by the legal requirements associated with these rights.

- Users may download and print one copy of any publication from the public portal for the purpose of private study or research.

- You may not further distribute the material or use it for any profit-making activity or commercial gain

If the publication is distributed under the terms of Article $25 \mathrm{fa}$ of the Dutch Copyright Act, indicated by the "Taverne" license above, please 


\title{
Connected Arrays of Dipoles for Broad Band, Wide Angle Scanning, Dual Polarized Applications: a Novel Solution to the Common Mode Problem
}

\author{
Daniele Cavallo, TNO, The Hague, Netherlands / Eindhoven University of Technology, Eindhoven, Netherlands, \\ Tel: +31703740249, e-mail: daniele.cavallo@tno.nl \\ Andrea Neto, Delft University of Technology, Delft, Netherlands, e-mail: a.neto@tudelft.nl \\ Giampiero Gerini, Felix Smits, TNO, The Hague, Netherlands, e-mails: giampiero.gerini@tno.nl, felix.smits@tno.nl
}

\begin{abstract}
Wideband connected arrays of dipoles are a very promising solution for broadband, wide-angle scanning phased arrays. Unlike tapered slot antennas, connected arrays can operate over wide bandwidth maintaining polarization purity. However, an open issue for the practical implementation of these arrays is the propagation of common-mode currents along the differential feeding lines. A solution for this problem is here proposed and is constituted by a loop-shaped transformer that acts as common-mode rejection circuit. Simulated results are presented for connected arrays of dipoles for both linear and dual polarization, with $30 \%$ relative bandwidth (from 10.7 to $14.5 \mathrm{GHz}$ ) and scanning capability up to $45^{\circ}$ for any azimuth.
\end{abstract}

\section{INTRODUCTION}

Wideband arrays are receiving a lot of attention because they enable new system functionality and increased integration in environments where multiple sensors are competing for the same physical space. In particular, a wideband aperture could be shared between radar and communication systems (operating at different frequencies) but could also support systems that require very large continuous bandwidths, e.g. Electronic Support Measures (ESM).

The field of wideband radiators is currently dominated by Vivaldi like antennas. However, these have a high profile, are difficult to integrate in planar (and conformal) arrays and they are known to radiate strong cross-polarized fields, especially in the diagonal plane $\left(\varphi=45^{\circ}\right)$.

A novel trend emerging is the use of planar arrays of long dipoles or slots periodically fed at Nyquist intervals which can guarantee both the broad band and the low cross polarization: connected arrays. These antennas are planar radiators with very high mutual coupling between neighboring elements to enlarge the bandwidth. Physically touching connected arrays have been formally introduced by Hansen [1] and then further theoretically developed in [2]. Similarly wideband antenna concepts were also developed by Munk [3], who did not refer to the name connected arrays but essentially realized the connection by means of capacitive loading at the edges of the dipoles.

A number of issues still limit the actual performance achievable from the practical implementation of connected arrays. In this paper, we will specifically target the problem related to the realization of the feeding network. As for all wideband phased arrays differentially fed, also for connected arrays the balanced transmission lines used to feed the elements can support both differential and commonmode propagation [4-5]. This latter is undesired, since it can give rise to resonances that ruin the array performance. Due to electrical connection between the array elements and high mutual coupling, standard baluns typically used to avoid common-mode resonances are not effective for connected arrays [6].

Therefore, a novel Printed Circuit Board (PCB) solution to avoid common-mode resonances, without resorting to active components or Monolithic Microwave Integrated Circuit (MMIC) technology, is proposed in this paper. It consists in a loop-shaped component that constitutes an open circuit for the common mode, while representing a small impedance change for the differential mode. The use of such commonmode rejecting loop allows the design of a dual polarized array of connected dipoles, according to the design rules specified in [7]. The specific application considered is aircraft-to-satellite communication for in-flight entertainment [8]. For simultaneous receive and transmit operation, a band from 10.7 to $14.5 \mathrm{GHz}$ is required.

\section{COMMON-MOde RESONANCES}

A detailed analysis of common-modes resonances in connected array of dipoles and another possible solution to the common-mode problem suitable for PCB manufacturing was reported by some of the present authors in [6]. In this section, we only give an explicative example to quantify the impact of the common-mode propagation on the array 


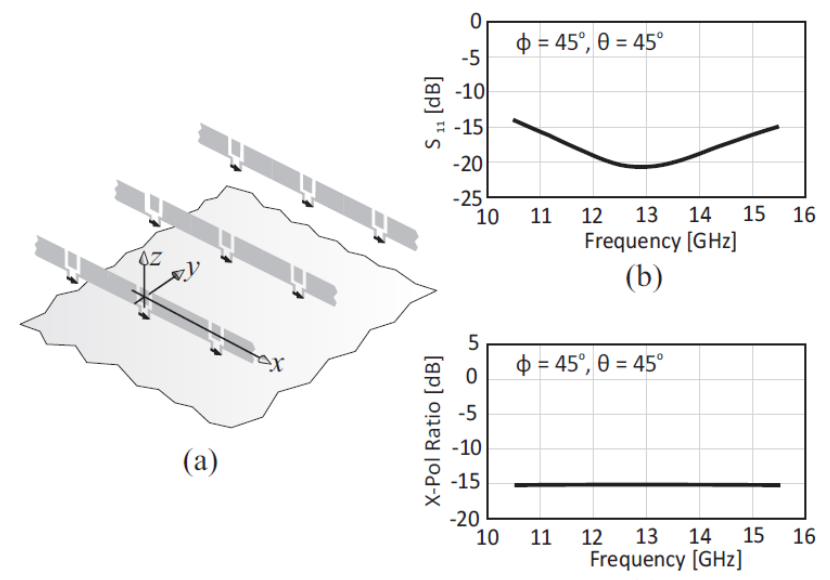

(c)

Figure 1 - Connected array of dipoles without vertical feeding lines: (a) array geometry; (b) active reflection coefficient and (c) X-pol levels at $\theta=45^{\circ}, \varphi=45^{\circ}$

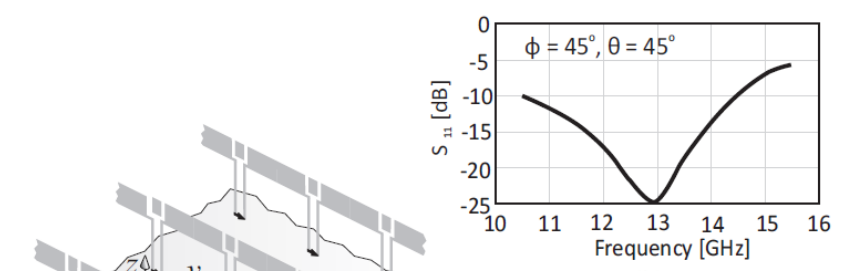

(b)

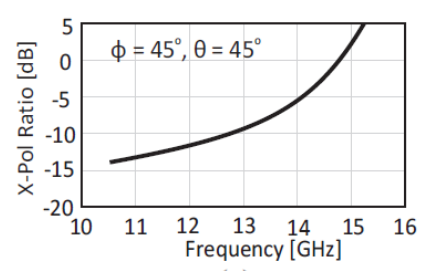

(c)

Figure 2 - Connected array of dipoles with vertical feeding lines: (a) array geometry; (b) active reflection coefficient and (c) X-pol levels at $\theta=45^{\circ}, \varphi=45^{\circ}$

performance. Figure 1(a) shows the geometry of an array of connected dipoles in the presence of a backing reflector, when the elements are fed at the dipole level, without the inclusion of vertical transmission lines. Figure 1(b) shows the active reflection coefficient of an array unit cell in infinite array environment, for scanning direction equal to $\theta$ $=45^{\circ}$ on the diagonal plane $\left(\varphi=45^{\circ}\right)$. For the same observation angle, the X-pol level (Fig. 1(c)) is about -15 $\mathrm{dBs}$, according to the third definition of cross polarization by Ludwig, [9]. Note that this value of X-pol is typical of perfectly linear radiating currents oriented along the $x$ - or $y$ axis. Figure 2 refers to a similar array geometry, in which the same dipole elements are fed by vertical co-planar strip (CPS) lines, in order to reach the ground plane level, where the feed is located (Fig. 2(a)). It can be observed in Fig. 2(c) that in this case the X-pol level rapidly increases with frequency. Such degradation is attributable to commonmode current propagation in the CPS lines. It is important to

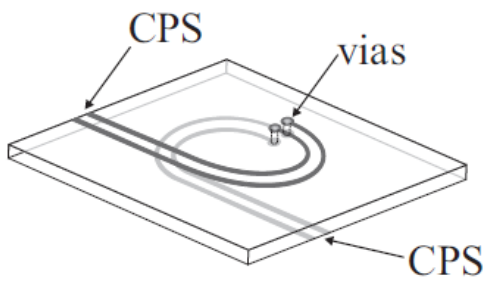

Figure 3 - Geometry of the loop-shaped transformer for common-mode rejection.
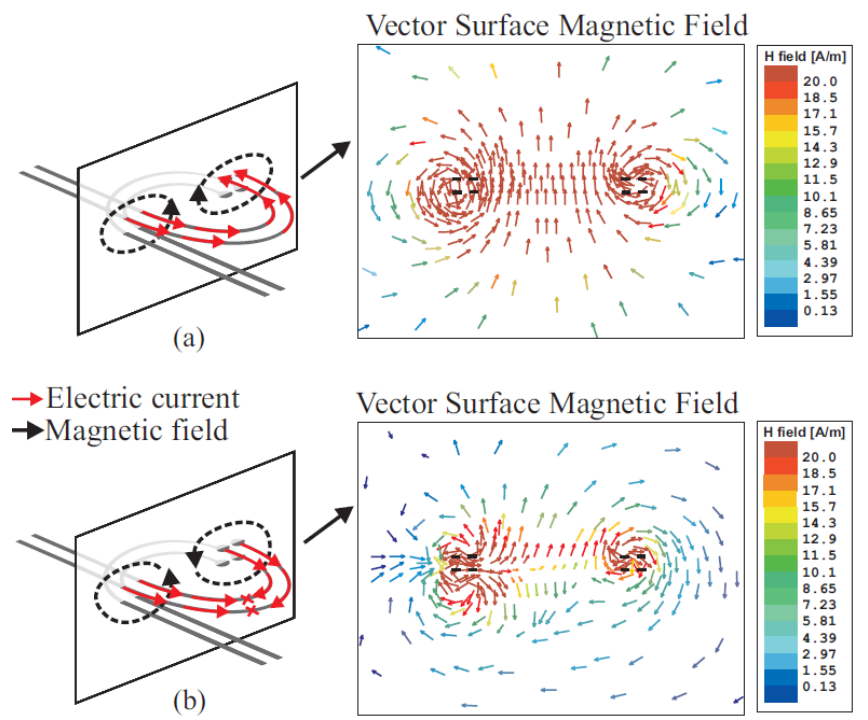

Figure 4 - Schematic of the vector current distribution and vector magnetic field on a transverse section of the loop calculated via Ansoft HFSS at (a) $7 \mathrm{GHz}$ and (b) $15 \mathrm{GHz}$

note that, even when the array is well matched, for instance at $14 \mathrm{GHz}$, the X-pol assumes very high levels (about -5 $\mathrm{dBs}$ ). Thus, the effect of common-mode resonances on the array efficiency should not be analyzed in terms of matching properties. The usable bandwidth should be defined by the $\mathrm{X}$-pol levels rather than the matching characteristics.

\section{LOOP-SHAPED FEEDING STRUCTURE FOR COMMON-MODE REJECTION}

In order to reject common-mode propagation on the vertical feeding lines, we consider a loop-shaped component as in Fig. 3. The loop radius is $1.06 \mathrm{~mm}$ and the loop is printed on a $0.254 \mathrm{~mm}$ thin dielectric substrate with permittivity 2.2 . When a common-mode input is applied, at low frequencies the currents flowing in the loop are equal in phase (Fig. 4(a)), thus the loop only behaves as a small series inductance for the common mode. As the frequency gets higher, different portions of the loops are flown by currents with different phases (Fig. 4(b)). Figure 4 shows the magnetic field in a cross section of the loop structure, calculated via Ansoft HFSS [10], at 7 and $15 \mathrm{GHz}$, respectively. 
At low frequencies, the currents flowing in the loop are equal in phase, thus the loop only behaves as a small series inductance for the common mode. As the frequency gets higher, different portions of the loops are flown by currents with opposite phases, generating cancelling magnetic fields, which in turn produce a magnetic field circuitation with close to zero contributions in the center of a cross section of the loop. As a consequence, at frequencies higher than a certain threshold, the average distributed inductance of the loop becomes lower as the magnetic fields do not add up coherently any longer. In a frequency range of more than an octave, the characteristic inductance will tend to very low values, creating a strong impedance discontinuity.

This effect is quantified in Fig. 5, by the S-parameters pertaining to differential (a) and common mode (b). A -10 $\mathrm{dBs}$ common-mode rejection is observed from about 9 to 22 $\mathrm{GHz}$, while no significant mismatch is experienced by the differential mode up to $18 \mathrm{GHz}$. The S-parameters pertain to the geometry depicted in Fig. 6. Since the active input impedance of a connected dipole element typically exhibits high values (about 400 Ohms), the loop can be used to implement an impedance transformation for the differential mode. To this aim, a two-section transformer from 400 to $200 \mathrm{Ohms}$ and a tapered line from 200 to $160 \mathrm{Ohms}$ have been implemented. The loop is printed on a dielectric substrate with $h=0.254 \mathrm{~mm}$ and relative permittivity 2.2 . Two inverters have been added to compensate for the slightly different radius of the inner and outer conductors within the loop, thereby reducing the spurious radiation of the loop when a differential input is applied.

\section{Array Performance}

Figure 7 shows the X-pol levels pertinent to an array of connected dipoles with and without vertical feeding lines, compared with the array including the loop-shaped feeding structure proposed in this paper. It is evident that, when the common-mode rejection loop is used, the degradation of polarization purity introduced by the vertical lines is strongly mitigated over the bandwidth of interest. In fact, the $\mathrm{X}$-pol ratio becomes lower than $-17 \mathrm{dBs}$ over more than $40 \%$ relative bandwidth.

These results pertain to a differential excitation located at the ground plane level. A more realistic coaxial feed requires the inclusion of a transition from CPS to microstrip (MS). A simple CPS-to-MS transition would introduce a further unbalance of the current along the differential lines, giving rise to a resonance as shown in Fig. 8. To avoid this problem, a sleeve balun has been designed. The resulting performance of the overall structure are presented in Fig. 9, which shows the geometry of the array unit cell, the active reflection coefficients for broadside and for $\theta=45^{\circ}$ in the main planes (normalized to an input impedance of 160 Ohms), and the X-pol ratio for $\theta=45^{\circ}$ and $\varphi=45^{\circ}$. A (a)

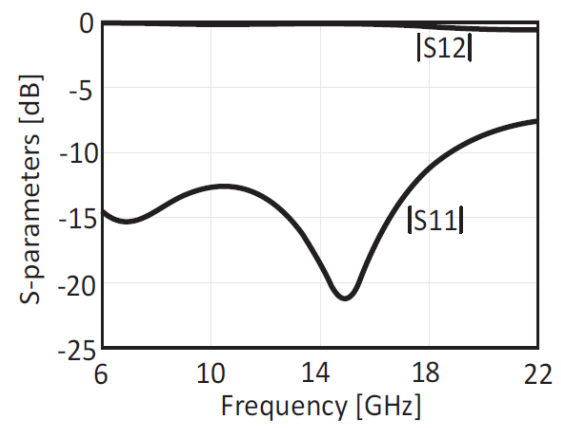

(b)

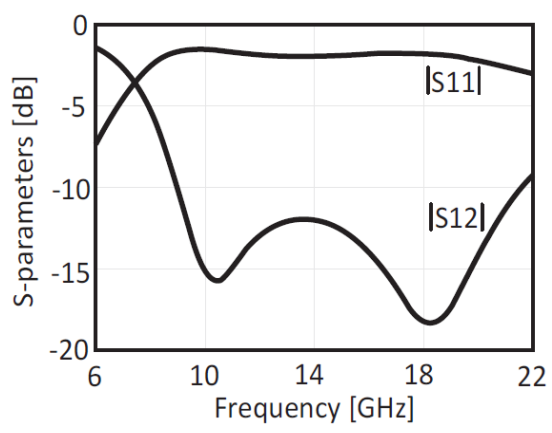

Figure 5 - S-parameters of the loop in Fig. 6 pertinent to (a) differential mode and (b) common-mode.

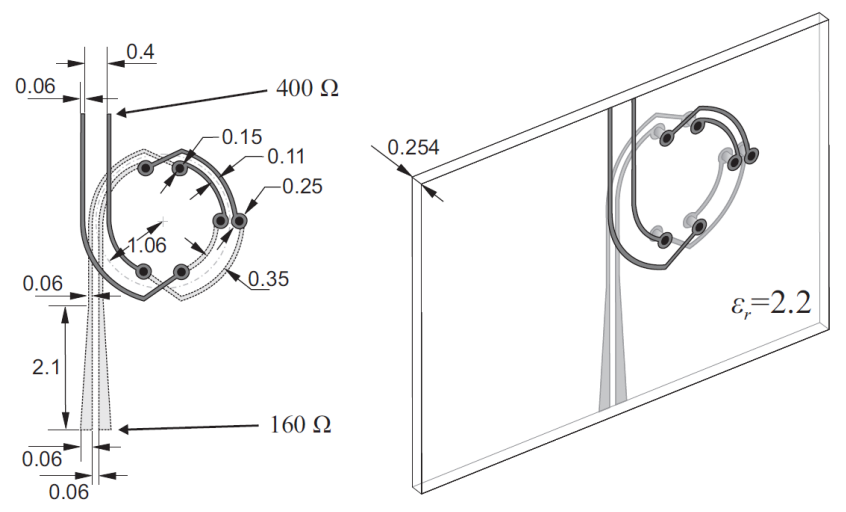

Figure 6 - Dimensions (in $\mathrm{mm}$ ) of the loop-shaped transformer.
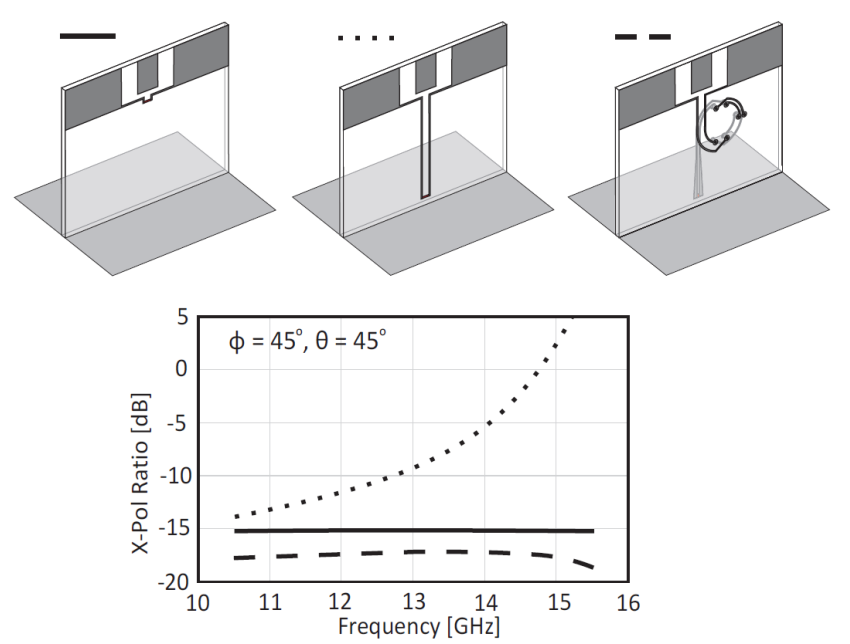

Figure 7 - Performance of the loop when included in the dipole array unit cell. 

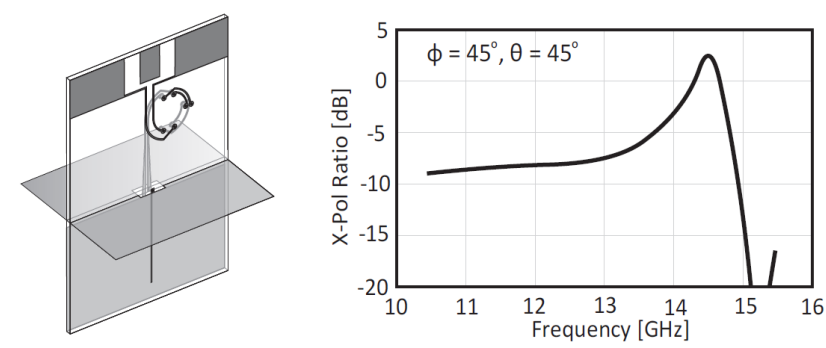

Figure 8 - Unit cell geometry and X-pol performance when a CPS to microstrip transformation is introduced.
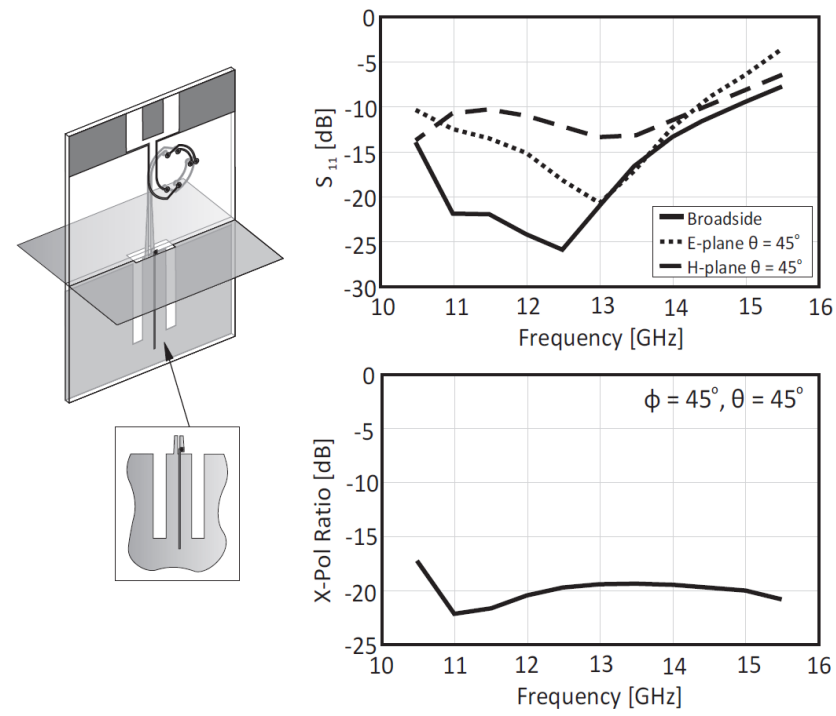

Figure 9 - Unit cell geometry and performance in terms of matching and $\mathrm{X}$-pol, with loop and sleeve balun.

reflection coefficient lower than $-10 \mathrm{dBs}$ is achieved over more than $30 \%$ relative bandwidth and the $\mathrm{X}$-pol level is at least $-14 \mathrm{dBs}$ lower than the copular component. The array periodicity is $8.2 \mathrm{~mm}$ (about $0.4 \lambda$ with $\lambda$ being the connected wavelength at the highest frequency) and the overall profile of the array is $11.7 \mathrm{~mm}$ (about $0.57 \lambda$ ).

For the dual-pol array design, a slightly different loopshaped feed has been designed, as shown in Fig. 10. The radius of this loop is reduced with respect to the linear polarization case, from $1.06 \mathrm{~mm}$ to $0.8 \mathrm{~mm}$. The loop is composed of two quarter wave sections of CPS lines to implement an impedance transformation for the differential mode from 400 to $160 \mathrm{Ohms}$. In order to have two sections approximately equal to a quarter wavelengths at the highest frequency of interest, the point of transition has been rotated of $100^{\circ}$ with respect to the corresponding point for the previous configuration. The S-parameters of the loop are reported in Fig. 11, while the array performance is shown in Fig. 12. Considering the points of $-10 \mathrm{dBs}$ matching, a relative bandwidth of $35 \%$ is achieved, while the X-pol ratio is below $-18.5 \mathrm{dBs}$ over the operational bandwidth.
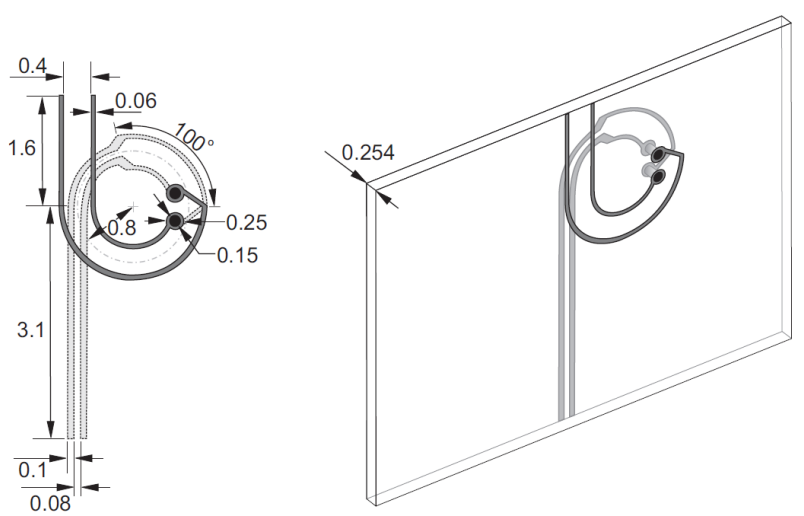

Figure 10 - Dimensions (in $\mathrm{mm}$ ) of the loop-shaped transformer for the dual-pol array.
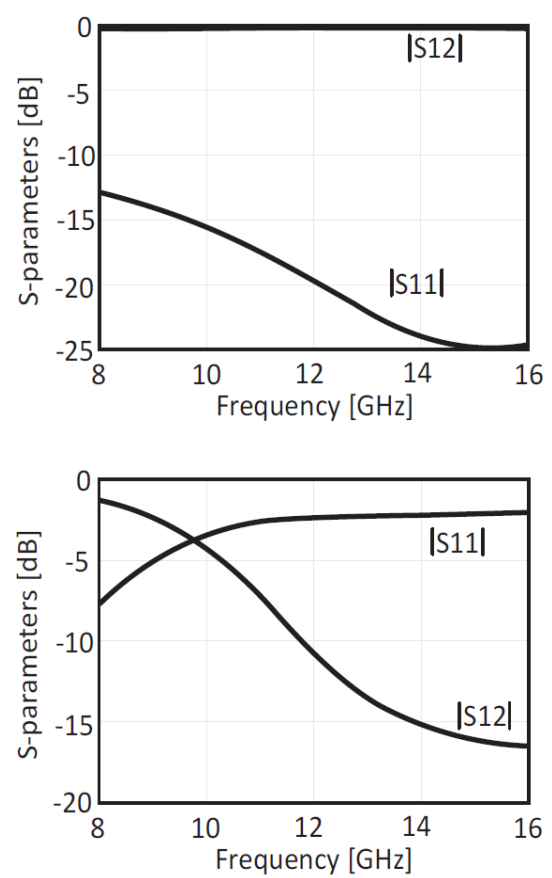

Figure 11 - S-parameters of the loop in Fig. 10 pertaining to (a) differential mode and (b) common-mode.

\section{CONCLUSIONS}

This paper presented an efficient practical way to design the feeding network of a connected array, as valid solution to common-mode resonances. The proposed loop-shaped feeding structure is based on PCB technology, to limit the costs and the complexity, without resorting to active component or to MMIC technology. The performance has been characterized via full-wave simulations performed via Ansoft HFSS. Simulated results show a $10 \mathrm{~dB}$ commonmode rejection over a more than one octave bandwidth ( 9 to $20 \mathrm{GHz}$ ). The inclusion of the loop component into the feeding lines of a connected array of dipoles has also been investigated. The design of a linearly polarized and a doubly polarized array has been presented. This latter has been 
shown to operate over $35 \%$ relative bandwidth when scanning up to 45 degrees, and X-pol levels below -18.5 dB within the entire scan volume. Even if only on paper, these results are believed to be the best reported for wideband wide-scanning applications, without penalty in polarization efficiency.

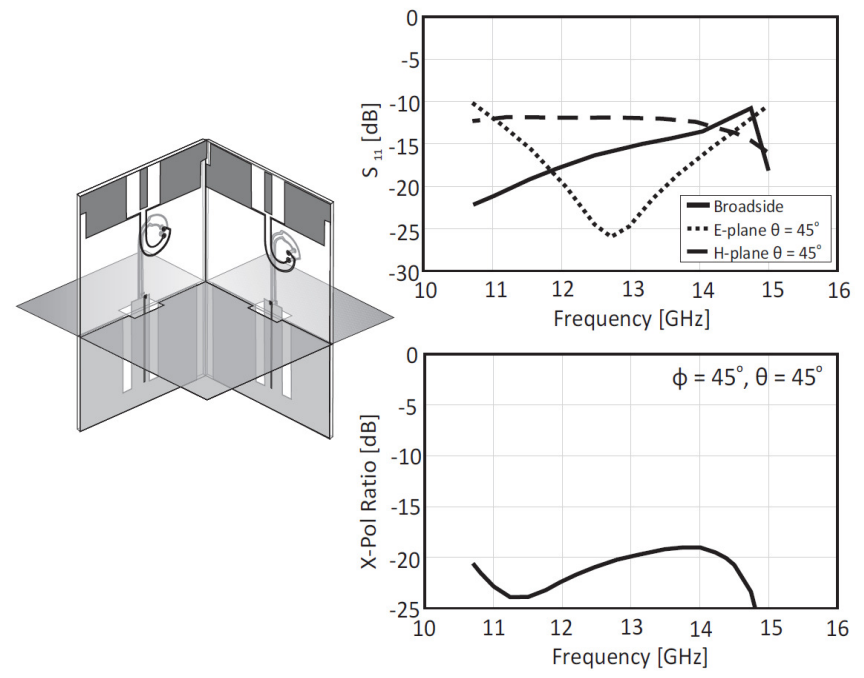

Figure 12 - Performance of the loop when included in the unit cell of a dual-pol connected dipole array.

\section{REFERENCES}

[1] R. C. Hansen, "Linear Connected Arrays," IEEE Antennas Wireless Propag. Lett., vol. 3, pp.154-156, 2004.

[2] A. Neto and J.J. Lee, "Ultrawide-Band Properties of Long Slot Arrays," IEEE Trans. Antennas Propag., vol. 54, no. 2, pp. 534-543, Feb. 2006.
[3] B. A. Munk, Finite Antenna Arrays and FSS, John Wiley \& Sons, Inc., 2003.

[4] S. G. Hay, J and D. O'Sullivan, "Analysis of commonmode effects in a dual-polarized planar connected-array antenna," Radio Science, Vol. 43, RS6S04, doi:10.1029/2007RS003798, Dec. 2008.

[5] E. de Lera Acedo, E. García, V. González-Posadas, J. Luis Vázquez-Roy, R. Maaskant, and D. Segovia, "Study and Design of a Differentially-Fed Tapered Slot Antenna Array," IEEE Trans. Antennas Propag., vol. 58, no. 1, pp. 68-78, Jan. 2010 .

[6] D. Cavallo, A. Neto, G. Gerini, "Printed-Circuit-Board Transformers to Avoid Common-Mode Resonances in Connected Arrays of Dipoles". IEEE Trans. Antennas Propag., vol. 58, no. 8, Aug. 2010.

[7] A. Neto, D. Cavallo, G. Gerini and G. Toso, "Scanning Performances of Wide Band Connected Arrays in the Presence of a Backing Reflector", IEEE Trans. Antennas Propag., vol. 57, no. 10, Oct. 2009.

[8] "Advanced Antenna Concepts for Aircraft in Flight Entertainment” (ACTIfE), ESA Estec Contract no. C19865.

[9] A. C. Ludwig, "The definition of cross polarization," IEEE Trans. on Antennas and Propagation, vol. AP-21, pp. 116-119, Jan. 1973.

[10] The homepage of Ansoft Corporation [Online]. Available: http://www.ansoft.com/ 